\title{
Summary of Solar Experience with the Soiling of Optical Surfaces
}

Patrick J. Call
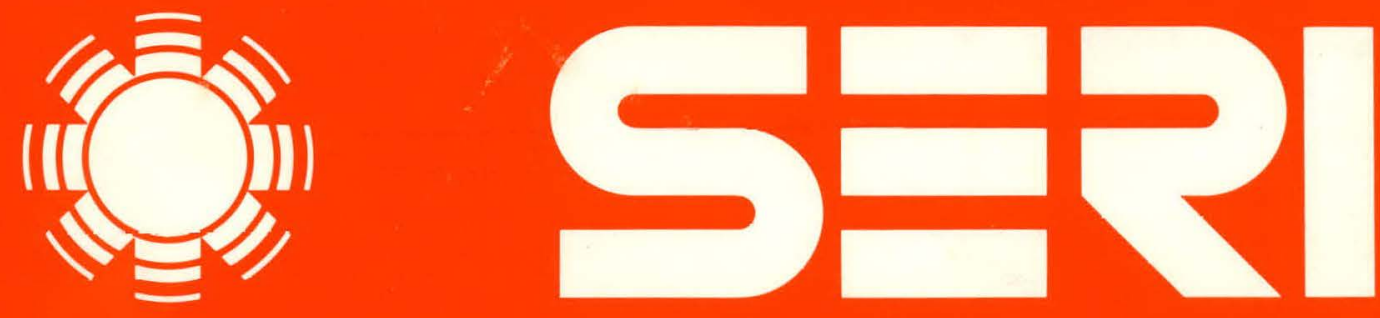

Solar Energy Research Institute A Division of Midwest Research Institute

1617 Cole Boulevard

Golden, Colorado 80401

Operated for the U.S. Department of Energy under Contract No. EG-77-C-01-4042 


\section{DISCLAIMER}

This report was prepared as an account of work sponsored by an agency of the United States Government. Neither the United States Government nor any agency Thereof, nor any of their employees, makes any warranty, express or implied, or assumes any legal liability or responsibility for the accuracy, completeness, or usefulness of any information, apparatus, product, or process disclosed, or represents that its use would not infringe privately owned rights. Reference herein to any specific commercial product, process, or service by trade name, trademark, manufacturer, or otherwise does not necessarily constitute or imply its endorsement, recommendation, or favoring by the United States Government or any agency thereof. The views and opinions of authors expressed herein do not necessarily state or reflect those of the United States Government or any agency thereof. 


\section{DISCLAIMER}

Portions of this document may be illegible in electronic image products. Images are produced from the best available original document. 
Printed in the United States of America Available from:

National Technical Information Service

U.S. Department of Commerce

5285 Port Royal Road

Springfield, VA 22161

Price:

Microfiche $\$ 3.000$

Printed Copy $\$ 4.00$

\begin{abstract}
NOTICE
This report was prepared as an account of work sponsored by the United States Government. Neither the United States nor the United States Department of Energy, nor any of their employees, nor any of their contractors, subcontractors, or their employees, makes any warranty, express or implied, or assumes any legal liability or responsibility for the accuracy, completeness or usefulness of any information, apparatus, product or process disclosed, or represents that its use would not infringe privately owned rights.
\end{abstract}


SERI /TP-334-478

UC CATEgORIES: $59 \mathrm{c}, 62 \mathrm{e}, 63 \mathrm{c}$

SUMMARY OF SOLAR EXPERIENCE WITH THE SOILING OF OPTICAL SURFACES

PATRICK J. CALL

FEBRUARY 1980

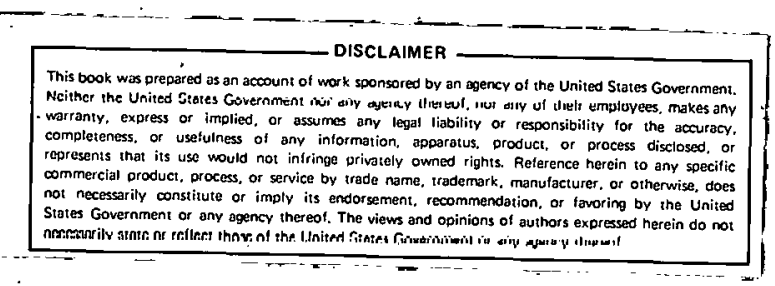

Prepared Under TASK No. 3458.00

Solar Energy Research Institute

1536 Cole Boulevard

Golden, Colorado 80401

A Division of Midwest Research Institute

Prepared for the

U.S. Department of Energy

Contract No. EG $\cdot 77 \cdot \mathbf{C} \cdot 01 \cdot 4042$ 
$i=$

\section{PREFACE}

This report summarizes the results of a workshop held 16-17 July 1979, in Denver, Colo., to discuss the effects of soiling on optical surfaces of solar energy conversion systems. Workshop participants .

Carl Maag

Alan Hoff man

David H. Kaelble

Michael A. Lind

Richard B. Pettit

John Vitko

Peter Roth

Gaylord W. Penney

William Carroll
Jet Propulsion Laboratory (JPL)

JPL

Rockwell Science Center

Battelle Pacific Northwest Laboratories

Sandia Albuquerque Laboratories (SAL)

Sandia Livermore Laboratories

SAL

Carnegie Mellon University

JPL

extensively reviewed this paper.

Presented here is a succinct status report on the state of understanding and the important concerns involved in this highly important problem.
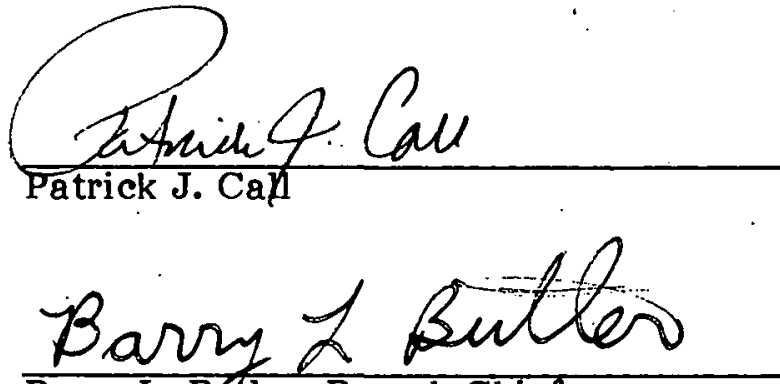

Barry L. Batler, Branch Chief

Materials Branch

Approved for:

SOLAR ENERGY RESEARCH INSTITITTF.

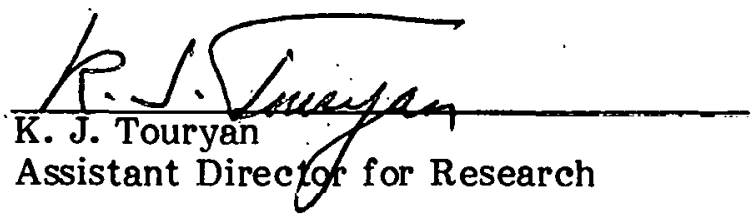




\section{INTRODUCTION}

Accumulation of air-borne particulates and aerosols on the optical surfaces of solar energy conversion systems results in undesirable absorption and scattering of the solar energy, adversely affecting performance.

This report summarizes the results of a workshop held on 16-17 July 1979 to discuss available experimental data, current and planned experimental investigations, directly applicable optical principles, and relevant theory. The results of the workshop are summarized in terms of the magnitude of effects on various types of systems and the effects of location, surface properties, and natural/artificial removal. The economics of prevention, tolerance, and removal are also summarized. Results are discussed in greater technical deptli by túpic.

\section{OBJECTIVES}

The primary objectives of the workshop were:

- to increase the effectiveness of current and future work via communication among investigator3,

- to make a preliminary determination of the magnitude of the problem from available information, and

- to interact with discipline specialists in related (nonsolar) industries and technologies.

The first two objectives were accomplished as described in this report. Contacts were established for future interactions with other technologies, but outside participation was seriously limited. Future meetings should include specialists in: (l) fine particles with emphasis on atmospheric pollution analysis and control; and (2) surface/adhesion physics.

The workshop identified near-term needs for data and correlations to reduce uncertainty in the estimates of system effects and some longer range approaches to the development of prevention and cleaning techniques.

Changes in reflectance or transmittance discussed in this report are expressed in absolute percentage. These numbers could also be expressed in terms of changes in reflectance units. Thus a change in reflectance from 0.60 to 0.50 reflectance units $(\rho=0.10)$ is reported as a $10 \%$ effect.

\section{SUMM ARY}

The magnitude of the effect of air-borne contaminants depends on system optical design, on location-dependent contaminants, on location-dependent and seasonal climate, on the optical component material, and on natural or artificial removal. The specular reflectance of mirror samples in Albuquerque decreases 0.5-1.0\%/day during the first few days (in the absence of rain) and appears to reach a pseudoequilibrium band with a mean 
at $-10 \%$ loss over a few months [1].* There are major oscillations depending on weather. Reflectance can be restored to within 1-2\% of the original value by contact and noncontact cleaning (including high pressure water jets without detergents). For flat-plate photovoltaics (optics would indicate a similar eff ect for flat-plate thermal collectors if differences in spectral sensitivity are ignored), short-term degradation in output current of $6-7 \% /$ month has been observed during rain-free periods in Pasadena, Calif., independent of surface materials (glass, polymers, and silicones). This effect corresponds to changes in the normal hemispherical transmittance. Over longer periods ( $>$ l year) the net accumulation, including effects of natural removal, results in measured degradation ranging from $2 \%$ for glass surface modules in Arizona to $-30 \%$ for silicone surface modules in high-pollution urban locations (New York and Cleveland) [2]. Specular properties have not been measured at these locations.

High concentration ratio reflecting structures with receiver aperture acceptance angles of less than five degrees (e.g., paraboloidal dishes and heliostats for central receiver) are more affected by soiling because only the specularly reflected energy reaches the receiver. For systems with low concentration ratios (e.g. flat plates, evacuated tubes, compound parabolic concentrators with aperture acceptance angles greater than five degrees), much of the scattered energy reaches the receiver, making these systems less sensitive to contamination. There is inadequate information to quantitatively compare the effects as a function of receiver acceptance angle. The differences depend on the relative contributions of absorption and scattering by the contaminants, but highly concentrating systems are probably five times more sensitive than flat plates.

Although the available data are limited to flat-plate photovoltaic modules, there is clear evidence of very significant location dependence of contamination effects [2]. There are even significant differences in the effects at sites separated by only a few miles (Cleveland). Valid reasons support the qualitative nature of the observed results; however, quantitative prediction or allocation to various causes is not yet possible. Quantitative prediction of soiling effects on solar concentrators from local pollution and climate data is a desirable, long-range goal.

The surface optical effects of particular contaminants are determined by the optical properties and the quantity, size, and shape of the accumulated particles. The timedependent adhesion of contaminants to the optical surface is also determined initially by the particle size and shape as well as the particle and surface chemistry. The leaching of molecular species (e.g., organics and salts) in the presence of moisture and the presence of dissolved chemicals in rain and dew probably dominate the adhesion over longer time periods. The amount of contaminant remaining after one or a series of natural (wind, rain, etc.) or artificial cleanings is determined by particle adhesion. Rain or snow generally removes contaminants and improves optical performance. The effectiveness of removal is related to the frequency, intensity, and duration of the precipitation [3].

Based on the effects on photovoltaic modules, the initial accumulation of dust does not appear to depend upon the type of optical material; however, the effectiveness of removal by rain or snow is highly material dependent. Removal by rain is least effective for silicone rubber, somewhat more effective for a silicone "hard coat," and most effective for glass and plexiglas [2]. Preliminary data indicate that natural removal from glass and plexiglas is approximately the same. Although it is clear that the optical properties

* Recent measurements (K. B. Pettit, private communication) indicate that this pseudoequilibrium continues to degrade with an average loss of $19 \%$ after 1.8 years. 
of soft polymer surfaces can be more irreversibly degraded by soiling than the same properties of glass, the effects on materials of intermediate hardness and the relationship to chemical and physical properties can only be postulated at this time.

The optical performance of glass surfaces can be restored to the original condition by cleaning, at least for periods of a year or two. Silicone rubber surfaces are hard to clean after extended exposure, and full restoration may not be possible with practical methods. The choice between tolerance of dust accumulation with natural removal and regular cleaning will be made primarily on economic considerations. For some materials and locations, contact cleaning (brush, sponge, squeegie) and detergents may not be required. Tests indicate that high pressure tap water restores the reflectance of glass mirrors, at least for a number of cycles [3]. The effect of regular cleaning over long periods of time needs to be examined further. There are currently inadequate data on the rate and magnitude of dust accumulation for various materials and locations to allow a decision between toleration and cleaning or to define a cost-effective cleaning strategy.

The general conclusions that appear in this summary are explored in somewhat greater depth in the following technical discussions.

\section{TOPICAL DISCUSSION}

\section{Optical and Systems Effects}

The soiling of optical surfaces is of interest to designers of solar energy conversion systems because contamination, through scattering and/or absorption, can lead to both reversible and irreversible degradation of optical performance. To quantify the effect of contaminants on transmitting, reflector, and absorber surfaces, it is necessary to understand the energy balance in the specific optical system under consideration. Figure 1 illustrates the possible effects on the three surfaces of interest. For transparent optical elements, incident solar energy is: (1) transmitted directly; (2) absorbed; (3) backscattered; (4) or forward scattered. In flat-plate photovoltaic and thermal collectors, only the absorbed and back-scattered energy is lost due to contamination; the forwardscattered components reach the receiver. For high-concentration lens systems most of the forward scattered energy also is lost. For superstrate (second surface) mirrors, the energy is (1) specularly reflected; (2) scattered; or (3) absorbed. Since the beam passes through the contaminant layer twice, the scattering and absorption effects are greater than for transparent elements. Plane-mirror-enhanced flat-plate collectors would be the least affected, since all of the specular and part of the scattered energy would reach the receiver. For absorber surfaces the major loss is back scattering at all angles; however, cavity geometry minimizes even this effect. Over long periods of time the buildup of a contaminant layer at the receiver surface may increase the emittance if a selective absorber coating is used.

For transmitting materials and reflectors, the relative importance of scattering versus absorption is determined by the nature of the contaminants and by the system's aperture acceptance angle and focal length. Flat-plate thermal and photovoltaic devices recover much of the scattered sunlight; however, point-focus systems are extremely sensitive to scattering as well as to absorption.

Detailed studies by Sandia Laboratories in Albuquerque, N. Mex., and the Jet Propulsion Laboratory have explored the magnitude of the optical effects. Sandia Laboratories has studied the effects of southwestern U. S. desert dust on silver/glass mirror surfaces [1]. 


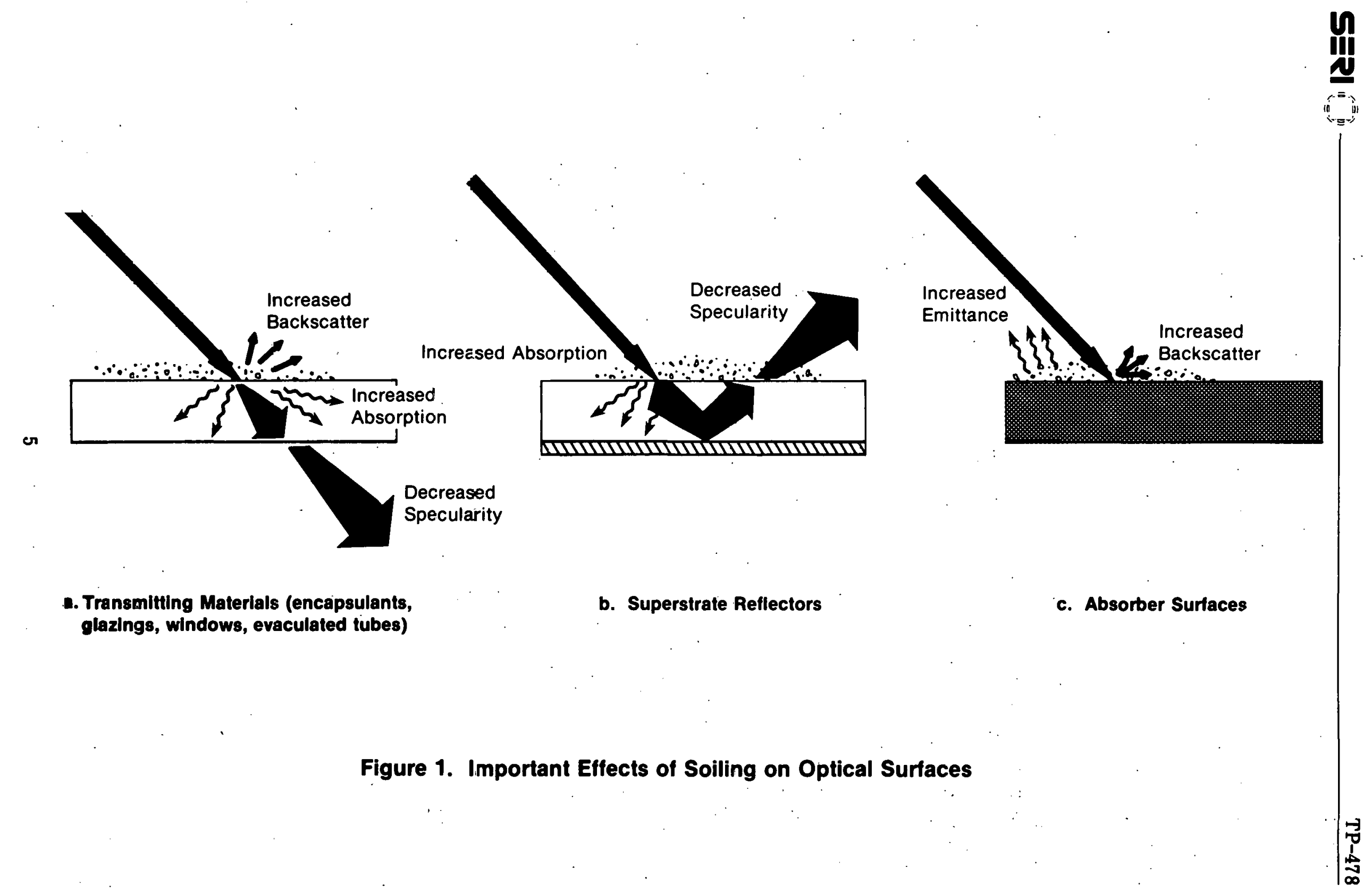


This work leads to several preliminary conclusions. The primary effect of desert dust appears to be very large angle scattering, especially at the shorter wavelengths of the solar spectrum. Calculations show that the scattering effect is greatest for particles of diameter 0.3 to $2 \mu \mathrm{m}$, and thus small particles represent the largest problem. Attempts to accelerate exposure to dust by using a wind tunnel have suffered to date from a number of experimental problems; however, one apparent trend is that exposure to dust by dry deposition produces a linear decrease in specular reflectances as a function of exposure time.

The Sandia work indicates that short-term decreases in specular reflectance for silver glass mirrors of 0.5 to $1.0 \% /$ day can be expected. However, the asymptotic decrease in specular reflectance after a few months under natural cleaning conditions is a band with a mean of approximately $10 \%$ loss and peak-to-peak variations of 5 to $16 \%$. Continued exposure leads to further degradation. After 1.8 years a mean decrease in specular refleclunce of $19 \%$ and extremes of 16 to $23 \%$ are nhserve.d.* Martin Murieltu [4] has studied the soiling of heliostats near Denver, Colo., and has reported that a high initial soiling rate of $0.2 \%$ /day loss in reflectance reduces to a monthly degradation of approximately $4 \%$.

Through JPL's Low Cost Silicon Solar Array (LSA) project, JPL, MIT/LL, and NASA Lewis Research Center have deployed flat plate PV modules at approximately 20 sites for the purpose of monitoring long term environmental durability, including the effects of contaminants on long term power production [2]. The flat plate configuration of the photovoltaic modules makes these experiments much less susceptible to scattering, and the sizable decreases in power output have been predominantly attributed to solar absorption by contaminant particles. Detailed optical characterization of test coupons (encapsulants) exposed in the field alongside the photovoltaic modules is being conducted by Battelle Pacific Northwest Laboratories, and the preliminary conclusions of this work corroborate the analysis that absorption by contaminants is a major contributor to power loss. Short term loss rates of 4-7\% per month are typical for the sites studied; however, the worst case (in New York City) shows a much higher rate ( $78 \%$ per month). The long-term asymptotic effect ranges from $25 \%$ to $60 \%$ under natural clcaning conditions depending on site and season. A phase II sludy mith $^{\text {is }}$ uindel'way to widen the range of sites and to gain more detailed understanding of the optical effects on a variety of test coupons.

To further understanding of the energy balance effects of contaminants, bidirectional reflectance measurements are needed to obtain wlde angle scutteling profiles. If thc optical properties of the contaminant are known, portable gloss meters may provide adequate in situ monitoring of surfaces. In addition to the optical properties of contaminants, the particle size distribution is an important parameter if scattering is a major concern. If optical absorption is the primary concern, the sensitlvity to the particle size distribution is smull, except as the partlcle size determines the sticking coefficiont and the cleanability of the surface.

*Private communication from R. B. Pettit, Sandia Laboratories, Division 5842, Albuquerque, NM 87115.

**Dr. Carl Maag, Principal Investigator, Jet Propulsion Laboratory, 4800 Oak Grove Dr., Pasadena, Calif. 91108.

"Such as those described in ANSI/ASTM D523-78. 


\section{Location}

As noted in the summary, dramatic differences in the magnitude of soiling effects have been observed even for sites close to each other. Local conditions which affect optical losses include at least some combination of the following factors (there may be others):

- quantity of atmospheric pollutants at the site;

- optical properties of particles - real ( $n$ ) and imaginary (k) parts of the index of refraction

- particle size, shape;

- surface chemistry and physics of particles and substrates;

- molecular constituents;

- type, frequency, and quantity of precipitation;

- humidity and dew cycles;

- wind and insolation;

- temperature cycles; and

- simultaneous and sequential occurrences.

The optical properties of typical dust by region, and in some cases by site, are needed to model accurately the optical effects of soiling. Predictive modeling will eventually be important for site assessment. At the present time, approximately one year of frequent data measurements (approximately weekly) is needed to characterize dust effects.

\section{Contaminants}

Although a considerable data base exists by region and site regarding the chemical, elemental, and physical characterization of dust particles, how this characterization affects the optical properties of solar energy conversion systems is not well explored. The Sandia Albuquerque experiments, which show scattering as a principal effect, are based on natural desert dust in the Albuquerque area. Laboratory-accelerated soiling experiments were performed using AC-spark-plug-standardized Arizona desert dust.* The JPL experiments, which show absorption to be a major contributor to the photovoltaic flat-panel power degradation, have a wider cross section of sites, primarily urban in character. A study of the optical properties of aerosols [5] shows that scattering dominates absorption in determining the extinction of sunlight in all environments. The attenuation coefficient $\left(\mathrm{km}^{-1}\right)$ for scattering is ten and two times larger than for absorption in rural and urban environments, respectively.

A preliminary conclusion from these two studies is that the inorganic desert particles have a rather low $\mathrm{k}$ value and that urban pollutants rich in soots. have a larger $\mathrm{k}$ value. In general, the composition of the contaminant also affects the sticking coefficient and the cleanability; however, data on this topic were not available at the soiling workshop.

\footnotetext{
*Obtained from Arizona Desert Dust, A. C. Spark Plug Division, GMC, P.O. Dox 1001,
} Flint, MI 4850 l. 
Information from other industries, the Environmental Protection Agency, and other aerosol programs needs to be studied with respect to solar optical systems. In particular, sticking coefficient, optical properties, and particle size distribution data are needed for potential solar sites. A simple technique to measure dust particle size distributions on surfaces could also be valuable. Preliminary results from the Sandia analysis indicate that for particles with diameters greater than $l \mu \mathrm{m}$, the particle size distribution on the surface of naturally weathered mirrors was similar to the particle size distribution measured in the atmosphere of the Southwest $[6,7,8]$; however, the orientation of the mirror during exposure and natural cleaning can have a significant effect on the size distribution of accumulated particles. For particles with diameters less than $1 \mu \mathrm{m}$, the density is greater than would be expected from the atmospheric particle size distribution, indicating that there may be some preferential adhesion of these small particles. These results are consistent with experiments that have shown increasing adhesion forces with decreasing particle size [9]. It was concluded that understanding contaminants is primarily an effort to access the information already collected from other programs and industries.

\section{Materials Surface Properties and Adhesion}

Although no systematic studies have been performed in the solar program to determine the role of the optical surface in contaminant adhesion and cleaning, considerable ancillary information is available from the field studies previously discussed. Photovoltaic arrays encapsulated with glass, silicones, and other polymers have been studied by JPL. Sandia Albuquerque, although predominantly studying silver/glass mirrors, has also evaluated some polymeric materials. Some tentative generalizations appear to be in order. Silicones, having the softest surface, show a significantly higher accumulative contamination effect. However, aside from the silicones, there appear to be only small differences between glass and the hard plastics in the tests run to date under natural cleaning conditions. In dirty urban environments, with natural cleaning, the difference between silicones and glass/hard polymers is greatest. The similarity between glass and the hard polymers is corroborated by Sandia studies and is somewhat surprising in view of the polymers' potential for greater electrostatic attraction and softer surfaces. The data base on material and site combinations will soon be expanded by an Industrial Process Heat Program contract with McDonnell Douglas, which will provide detailed observations for seven sites.*

Tin oxide coatings with a low surface energy appear to minimize dust adhesion in experiments conducted by Battelle Pacific Northwest** and Sandia Laboratories [9]. A thin film of tin oxide on a reflecting or transmltting elemenl furms a rugged, electrieally conducting, and transparent surface that might be used as both a dust- and abrasionresistant coating.

A potentially important effect observed for polymers is the leaching of low molecular weight molecules from the bulk of the polymer to the surface where they can react with dirt to provide increased adhesion [11]. A porous gel layer at the glass interface has also been observed [12] and may contribute to dust adhesion at glass interfaces.

*Sandia Laboratories purchase order No. 13-0261. Principal investigator: Virginia Morris, McDonnell Douglas Astronautics, 5301 Bolsa Ave., Huntington Beach, CA 92647.

**Preliminary observations from M. A. Lind, Battelle Pacific Northwest Laboratories, Battelle Blvd., Richland, WA 99352. Quantitative measurements are in progress. 
Several forces account for the adhesion bond between the contaminant and the surface in the initial contact stage. The primary forces are associated with the $1 / \mathrm{r}$ electrostatic, $1 / \mathrm{r}^{3}$ dipolar, and $1 / \mathrm{r}^{6}$ Van der Waals energies. Although these forces provide the initial attraction, increased adhesion may develop between the particle and the substrate in the presence of moisture. Leached materials from the particle/substrate or chemicals made available through rain or snow may form a glue with irreversible chemical bonds that are many times stronger than the fundamental physical forces. The topography of a surface may have a large effect on contaminant adhesion; however, as a specific example the high transmittance etched glass made by Honeywell does not exhibit anomalously high dust accumulation rates [13].

The importance of altering the surface chemistry or topography in mitigating the effects of soiling needs further investigation. Organic compounds exist that can be switched reversibly from the hydrophilic to the hydrophobic state; they may find application as surface coatings for solar optical elements [14]. Inorganic films that provide in one layer the appropriate surface energy, abrasion resistance, and ultraviolet protection for an underlying polymer may be a cost-effective solution. However, the cost of any such treatment must be weighed against refurbishment costs. Preliminary results indicate that cleaning of glass surfaces is a simple and reasonably inexpensive procedure [15].

In long-term contaminant accumulation studies on photovoltaic modules and transmitting glazings, it is exceedingly important that effects due to changes in the optical properties of the substrate material be separated from effects attributable to contaminants. In addition, the irreversible effects of cleaning must be accounted for.

\section{Natural Removal, Cleaning, and Preventive Maintenance}

Experiments performed by McDonnell Douglas indicate that washing of the mirror surface with high pressure tap water with a sheeting agent restores the specular reflectance to within $2 \%$ of its original value at a cost of $\$ 0.01-\$ 0.03 / \mathrm{m}^{2}$ per cleaning [16] Consideration of these costs in an optimized washing strategy indicates that cleaning costs would warrant an additional investment of approximately $\$ 600 /$ heliostat $\left(50 \mathrm{~m}^{2}\right)$ to prevent the effects of dust accumulation over a 30-year life. An independent study for flat-plate photovoltaics [17] also indicates that cleaning can be accomplished for $\$ 0.01-\$ 0.02 / \mathrm{m}^{2}$ per cleaning on a large scale. The photovoltaic study also examined the benefit of cleaning (plant net revenue from gained power) parametrically as a function of magnitude and rate of dust accumulation. For large arrays, as an example, the study concludes that automated washing is justified if the produced energy value exceeds $\$ 0.065 / \mathrm{kWh}$ and soiling frequently results in an $8 \%$ or greater loss in produced power.

The general conclusion from the Sandia and JPL studies indicates that under natural cleaning conditions the asympotic decrease in performance over a period of one year is approximately $15 \%$ for concentrating collectors in southwestern U.S. environments and as high as $60 \%$ for flat-plate collectors in urban environments. In assessing natural cleaning it is important to note that frequent (weekly) measurements are necessary and documentation of changes in weather conditions is important. Large changes in performance, both positive and negative, can be expected under certain weather conditions. Usually, frost, snow, rain, and heavy dew improve performance, that is, they reduce contamination-induced optical degradation [1]. Photovoltaic modules under observation in regions of intense and frequent rain (based on qualitative observations in Florida and Panama) 
remain significantly cleaner then counterparts elsewhere.* Recent experiments at Sandia Albuquerque [18] demonstrate that natural cleaning reduces the relative number of large particles while the number of small particles, with diameter less than $1 \mu \mathrm{m}$ (which are the most significant source of scattering for the solar spectrum), continues to increase with time. This observation may explain apparent discrepancies between data reported for changes in specular reflectance and hemispherical transmittance with soiling and natural cleaning.

Under certain conditions, such as rainstorms in combination with high wind and dust, dramatic decreases in performance can be expected; although the effects of humidity, wind, and temperature are not clear. In regions with long-term steady weather conditions, such as summer in the Los Angeles area when two to five months without significant rainfall is common, the conclusions of a natural cleaning study are greatly influenced by the season in which the study is conducted. In general, it appears that natural cleaning is more effective on glass than on polymers. Additional cleaning studies are being conducted under the auspices of Sandia Livermore Laboratories.

Techniques are being explored to prevent the buildup of soiling on optical surfaces. The simplest is to stow the optical element in a particular orientation when not in use. For heliostats, Sandia Albuquerque has discovered that a vertical stow position minimizes dust accumulation and maximizes natural cleaning. This orientation is preferred over either inverted or face up orientations; however, the vertical orientation may be impractical during periods of high winds or for trough collectors. Sandia Livermore Laboratories has solicited innovative ideas for preventive maintenance of mirror surfaces and has selected five projects to test feasibility and to compare costs with those of a regular cleaning schedule**. These techniques include covers and mechanical means of removing soiling as well as a study to address the effects of modified surface chemistry. JPL, Sandia Albuquerque, and the University of Arizona [19] have explored the effects of an applied electric field at or near the optical surface. The results are not consistent: JPL experiments have shown very little effect, while Sandia and the University of Arizona have found a marked reduction in the rate of soiling accumulation due to the electric fleld. It is likely that this discrepancy can be explained by the different geometries and experimental techniques employed.

A continuous air flow may also reduce soiling, although the effects of natural wind are unclear. Increased wind velocity for a given flux of particles decreases the rate of soiling, but increased winds can increase the density of airborne particulates and thus soiling rates. Humidity is undoubtedly a more important factor in dust accumulation than wind. High humidity leads to the agglomeration of small particles in the air and relative humidity above $65 \%$ dramatically increases the sticking coefficient of particles at an optical surface [9]. The effect on a reflector or glazing is determined by the surface temperature and local dew point, which may be considerably different from temperature and humidity measured away from the solar structure.

*Private communication, P. Jaffe, Jet Propulsion Laboratory, 4880 Oak Grove Dr., Pasadena, CA. 91108.

**"Solar Thermal Power Central Receiver Technology Status/Letter." Internal communication. Livermore, CA: Sandia Laboratories; Apr. 1979. 


\section{CONCLUSION}

The soiling of the optical surfaces of solar energy conversion devices can have a significant impact on the performance of these systems over extended periods. Research and development programs to characterize the soiling effects and to improve the protection and cleanability of optical surfaces are in progress at the Jet Propulsion Laboratory and Sandia Livermore Laboratories. Additional projects to gather information from the relevant experience of other industries are needed. Basic research leading to models that can predict the impact on optical performance based on material surface properties, meteorology, and aerosol data would be beneficial in designing site specific cleaning strategies.

\section{REFERENCES}

1. Freese, J. M. Effects of Outdoor Exposure on the Solar Reflective Properties of Silvered Glass Mirrors. Sandia Laboratories. SAND 78-1649; Sept. 1978.

2. Hoffman, A. Photovoltaic Module Soiling Studies: Phase I Investigations. LSA Project Task Report 5101-131 (JPL internal document). Pasadena, CA: Jet Propulsion Laboratory; Dec. 1979.

3. Non Contact Cleaning: Cleaning Agents and Techniques for Concentrated Solar Collectors. McDonnell Douglas Astronautics Company Report No. MDC. G8131. Sandia Laboratories Report SAND 79-1979; Sept. 1979.

4. Central Receiver Solar Thermal Power System, Phase I. Sandia Laboratories Report, Vol III. SAN-1110-77-2 prepared by Martin Marietta Corporation; April 1977.

5. Shettle, E. P.; Fenn, R. W. "Models of the Atmospheric Aerosols and Their Optical Properties". AGARD Conference Proceedings No. 183. Electromagnetic Wave Propagation Panel Symposium; Lyngby, Denmark; 27-31 October 1975.

6. Gillette, D. A.; Blifford, Jr., I. H. J. Geophysical Research. Vol. 79: 4068; 1974.

7. Quenzel, H. J. Geophysical Research. Vol. 75: p. 2915; 1970.

8. Blifford, Jr., I. H.; Ringer, L. D. J. Atmospheric Science. Vol. 26: p. 716; 1969.

9. Zimon, A. D. Adhesion of Dust and Powder. New York: Plenum Press; 1969.

10. Berg, R. S. Heliostat Dust Buildup and Cleaning Studies. Sandia Laboratories. SAND 78-0510; Mar. 1978.

11. Dahlquist, M. "Pressure Sensitive Adhesives," Chapter 5 in Treatise on Adhesives, Vol. 2 (R. L. Patrick, ed.). New York: Dekker; 1969.

12. Shelbv, J. E.; Vitko, Jr., J. Weathering of Low-Ion Float and CGW-0317 Glasses. SÁND 79-8225; May 1979. Surface Characterization of Weathered Low-Iron Float Glass, forthcoming. 
in

13. Lin, R. J. H.; Zimmer, P. B. Optimization of Coatings for Flat Plate Solar Collectors. Phase II, Final Report. Honeywell Systems and Research Center; 77SRC55; July 1977.

14. Kaelble, D. H. "Surface Energy Analysis of Bioadhesion." Polymers. Vol. 18: p. $475 ; 1977$.

15. Eason, E. D. Cost and Value of Washing Heliostats. SAND 78-8813; June 1979.

16. Blackman, J. B. Contact Cleaning. Interim Report on Non-working Heliostat Study-Effects of Dust Buildup. MeDonnell Douglas Corp.; MDCG7849; Mar. 1979 .

17. Engineering Study of the Module/Array Interface for Large Terrestrial Photovoltaic Arrays. Bechtel Corporation; ERDA/JPL/854698-77/1. Juné 1977 .

18. Roth, E. P.; and Pettit, R. B. "The Effect of Soiling on Solar Mirrors and Techniques Used to Maintain High Reflectivity" in Solar Materials Science (L. E. Murr, ed. New York: Academic Press; 1980.

19. Hoenig, S. A. "Keeping Dust off Optical Components." Applied Optics. Vol. 18: p. $1471 ; 1979$. 